\title{
Study on Energy-saving Lighting Design Method for Interior Zone of High-altitude Highway Tunnel
}

\author{
Qi Li ${ }^{1, *}$, Mingyang Chen ${ }^{1, * *}$, Wenjing Xie ${ }^{1, * * *}$, Qianyue Wang ${ }^{1, * * * *}$, Yue $\mathrm{Wu}^{1,{ }^{1 * * * *}}$, Chang Yang ${ }^{1, * * * * * *}$, Jiangming Zhen $^{1, * * * * * * *}$ \\ ${ }^{1}$ College of Architecture and Urban-Rural Planning, Sichuan Agricultural University, Dujiangyan, Sichuan, China
}

\begin{abstract}
In order to ensure the driving safety of high-altitude highway tunnel and effectively reduce the lighting cost, this paper adopts the method considering the influence of automobile headlights luminance which combines reaction time incremental theory at different altitudes and lighting design simulation calculation. The paper has studied the design pattern of high-altitude highway tunnel, which are dominated by fixed lighting and supplemented by automotive lighting. The results show that: to ensure driving safety, the luminance of the lighting design for interior zone of highway tunnel increases with the increasing altitude. Based on the supplementary lighting of automobile headlights, the lighting design standards for the interior zone of high-altitude highway tunnel(the altitude is $2000 \mathrm{~m}, 3000 \mathrm{~m}, 4000 \mathrm{~m}, 5000 \mathrm{~m}$ respectively) are $0.73 \mathrm{~cd} / \mathrm{m}^{2}, 0.82 \mathrm{~cd} / \mathrm{m}^{2}, 0.91 \mathrm{~cd} / \mathrm{m}^{2}, 1.0 \mathrm{~cd} / \mathrm{m}^{2}$.
\end{abstract}

\section{Introduction}

The number of high-altitude highway tunnel is increasing year by year ${ }^{[1]}$. A typical feature of the driving environment in high-altitude tunnel is the low-oxygen environment, which conduces to the increase of the reaction time of drivers, and is not conducive to safe driving ${ }^{[2]}$.Therefore, in the lighting design of tunnels in high-altitude environment, the lighting luminance needs to be improved if environmental factors are considered, but it is disadvantageous to reduce energy consumption, especially for super-long highway tunnels. This paper studies the automobile headlights, determines the luminance of the automobile headlights, and proposes the recommended design lighting values of high-altitude tunnel using the supplementary lighting. The values are not greater than the lighting standard of Guidelines for Design of Lighting of Highway Tunnels (JTG / T D70 / 2-01-201) ${ }^{[3]}$, and the impact of high-altitude environment is taken into account, making it easier to drive safely.

The evaluation standard for safe driving of highway tunnels is that the stopping sight distance of drivers is greater than the safe stopping sight distance. See the following formula (1).

$$
\mathrm{S}>\mathrm{S}_{\text {安 }}
$$

In the formula, $\mathrm{S}$ is stopping sight distance, $\mathrm{m} . \mathrm{S}_{\text {安 }}$ is safe stopping sight distance, $\mathrm{m}$.

Among them, stopping sight distance is the shortest driving distance needed when a vehicle encounters obstacles in front of it, including reaction distance, braking distance and safety distance. Code for Design of
Road Tunnel (JTG D70-2004) ${ }^{[4]}$ gives the safe stopping sight distance of different design speeds under different grades of highways.

The main factors influencing the safe driving of high-altitude highway tunnel include altitude, lighting luminance and driving speed ${ }^{[5]}$. As the altitude increases, the oxygen concentration in atmosphere is trending down, and drivers are prone to delayed response and blurred vision in hypoxic environments. The reaction time of drivers shortens as tunnel lighting luminance increases. Good tunnel lighting luminance helps drivers to judge driving conditions and ease fatigue ${ }^{[6]}$. The vehicle speed in the tunnel directly determines the braking distance and safety distance. The higher the vehicle speed, the longer the braking distance and safety distance.

\section{Lighting design standard for the interior zone of high-altitude highway tunnel}

Guidelines for Design of Lighting of Highway Tunnel (JTG/T D70/2-01-2014) ${ }^{[3]}$ consider the traffic flow and speed. Relevant values for the lighting design standard for the interior zone of high-altitude highway tunnel are determined as shown in Table 1.

Table 1. Recommended standards for luminance of interior zone.

\begin{tabular}{|c|c|c|c|}
\hline \multirow{3}{*}{$\begin{array}{c}\text { Speed(km } \\
/ \mathbf{h})\end{array}$} & \multicolumn{3}{|c|}{$L_{\text {in }}\left(\mathrm{cd} / \mathrm{m}^{2}\right)$} \\
\hline & \multicolumn{3}{|c|}{ One-way traffic } \\
\hline & $\begin{array}{c}N \geq 1200 \mathrm{veh} /( \\
h \cdot \ln )\end{array}$ & $\begin{array}{c}350 v e h /(h \cdot \ln )< \\
N<\end{array}$ & $\begin{array}{c}N \leq 350 v e h /(h \\
\cdot \ln )\end{array}$ \\
\hline
\end{tabular}

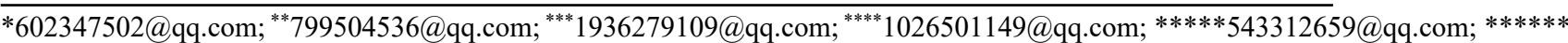

516226098@qq.com; ******2597552996@qq.com 


\begin{tabular}{|c|c|c|c|}
\hline & & $1200 v e h /(h \cdot \ln )$ & \\
\hline & \multicolumn{3}{|c|}{ Two-way traffic } \\
\hline & $\begin{array}{c}N \geq 650 v e h /(h \\
\text { ln })\end{array}$ & $\begin{array}{c}180 v e h /(h \cdot l n)< \\
N<650 \\
\text { veh } /(h \cdot \ln ) \\
\end{array}$ & $\begin{array}{c}N \leq 180 \\
v e h /(h \cdot l n)\end{array}$ \\
\hline 120 & 10.0 & 6.0 & 4.5 \\
\hline 100 & 6.5 & 4.5 & 3.0 \\
\hline 80 & 3.5 & 2.5 & 1.5 \\
\hline 60 & 2.0 & 1.5 & 1.0 \\
\hline $20-40$ & 1.0 & 1.0 & 1.0 \\
\hline
\end{tabular}

Considering the impact of the special environment at high altitudes, correcting and improving the minimum lighting luminance design value given by the criteria can effectively ensure the driving safety of drivers of high-altitude highway tunnels. The adverse impact of the plateau environment on driving safety is mainly shown up in the increased driver reaction time caused by the hypoxic environment. The relationship between the increase in reaction time and altitude is shown in formula $(2)^{[7]}$ :

$$
\tau=4.63 \mathrm{H} \times 10^{-5}-0.00217
$$

In the formula, $\tau$ is reaction time altitude correction, $s$. $\mathrm{H}$ is the altitude of tunnel, $\mathrm{m}$.

Among them, the reaction time is also affected by the environmental luminance, and the relationship between them is as shown in formula(3):

$$
\mathrm{T}=0.727+0.275 \mathrm{e}^{\frac{0.306-\mathrm{L}}{2.153}}
$$

In the formula, $\mathrm{T}$ is reaction time, $\mathrm{s} . \mathrm{L}$ is environmental luminance, $\mathrm{cd} / \mathrm{m}^{2}$.

According to formula(2) (3), the under different altitudes and different tunnel luminances is as shown in formula(4):

$$
\mathrm{S}=(\mathrm{T}+\tau) \mathrm{v}+\mathrm{S}_{1}+\mathrm{S}_{2}
$$

In the formula, $\mathrm{S}$ is stopping sight distance, $\mathrm{m} . \mathrm{v}$ is the speed, $\mathrm{m} / \mathrm{s} . \mathrm{S} 1$ is braking distance, $\frac{\mathrm{v}^{2}}{2 \mathrm{~g} \mu}\left(\mathrm{g}=9.8 \mathrm{~m} / \mathrm{s}^{2}, \mu\right.$ is friction coefficient with ground, and we let $\mu=0.8) . \mathrm{S}_{2}$ is safety distance, $\mathrm{m}$, and we let $\mathrm{S}_{2}=10 \mathrm{~m}$.

According to formula(1)and(4), the luminance values for interior zone of plateau highway tunnels (take $40 \mathrm{~km} / \mathrm{h}$ as an example) at different altitudes can be calculated. The calculation results are shown in Table 2.

Table 2. Recommended luminance for interior zone of plateau highway tunnel $(40 \mathrm{~km} / \mathrm{h})$.

\begin{tabular}{|c|c|c|c|c|}
\hline Altitude(m) & $\mathbf{2 0 0 0}$ & $\mathbf{3 0 0 0}$ & $\mathbf{4 0 0 0}$ & $\mathbf{5 0 0 0}$ \\
\hline $\begin{array}{c}\text { Recommended } \\
\text { luminance }\left(\mathrm{cd} / \mathrm{m}^{2}\right)\end{array}$ & 1.16 & 1.25 & 1.34 & 1.43 \\
\hline
\end{tabular}

It can be seen from Table 2 that as the altitude increases, the recommended luminance for interior zone of plateau highway tunnel increases, and they are greater than the recommended design luminance of $1.0 \mathrm{~cd} / \mathrm{m}^{2}$ in the current code $(40 \mathrm{~km} / \mathrm{h})$.

\section{Determination of luminance of automobile headlights of high-altitude highway tunnel}

The types of vehicles in high-altitude roads are mainly cars, trucks, SUVs and other models. With statistics in hand, the wattage of dipped headlights of each type of vehicle lamp is generally between $35 \mathrm{~W}-55 \mathrm{~W}$. The height of the light from the ground is between $0.5-1.2 \mathrm{~m}$ and the irradiation distance of automobile headlights is between $30 \mathrm{~m}-40 \mathrm{~m}$.

In order to convert the wattage of automobile headlights in the tunnel into the luminance on the ground in the tunnel, the illumination analysis software DIALux was used to establish a three-dimensional lighting model of the automobile headlights in high-altitude highway tunnel, which simulated the lighting conditions of dipped headlights in the dark tunnel. By establishing the model, the luminance of automobile headlights of high-altitude highway tunnel was obtained and determined.

The size of the tunnel model was $1000 \mathrm{~m}$ long, the clear width of the inner contour of tunnel lining was $9.8 \mathrm{~m}$, and the height of the inner vault of the tunnel was $7.05 \mathrm{~m}$. The lamps were arranged in the middle of the tunnel plane. About parameters of the automobile headlights in the model, the distance between the headlights was set to $1.0 \mathrm{~m}$, the type of light source was LED, the height of the light from the ground was $0.6 \mathrm{~m}$, the wattage of dipped headlights was $40 \mathrm{~W}$, the luminous lux was $40591 \mathrm{~m}$, the luminaire light output ratio was $67.6 \%$, the luminous efficiency was $101.5 \mathrm{~lm} / \mathrm{w}$, and the scattering angle was $30^{\circ}$. The specific model diagram is shown in Figure 1.

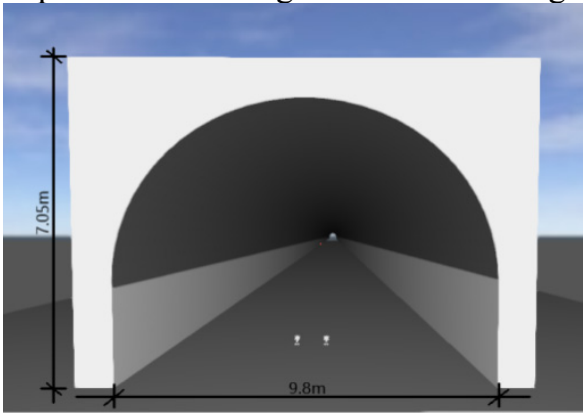

(a)Tunnel model size.

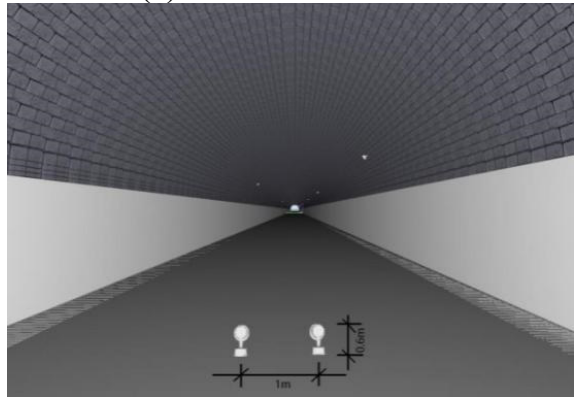

(b) Dimensional drawing of automobile headlights model.

Figure1. Dimensional drawing of tunnel and automobile headlights model 
The illuminance value of automobile headlights calculated by DIALux modeling should be converted into luminance value to be algebraically solved with the luminance values of plateau highway tunnel. When the illuminance value is converted to the luminance value, the reflectivity of the ground needs to be considered. Tunnel pavements are mostly asphalt or cement. According to Specifications for Design of Ventilation and Lighting of Highway Tunnel(JTJ026.1-1999) [8] , the average illuminance of asphalt pavement is generally 15-22 times of luminance, and that of cement pavement is generally 10-13times of luminance. Given that the pavement of the plateau tunnel is mostly cement pavement, in order to obtain the lowest value of the average luminance of dipped automobile headlights, $1 \mathrm{~cd} / \mathrm{m}^{2}=131 \mathrm{x}$ is used to convert the illuminance and luminance. Illuminance and luminance values of dipped automobile headlights in tunnel are shown in Table3.

Table 3. Illuminance and luminance values of dipped automobile headlights in tunnel.

\begin{tabular}{|c|c|c|c|}
\hline $\begin{array}{c}\text { Average } \\
\text { illuminanc } \\
\mathrm{e}\end{array}$ & $\begin{array}{c}\text { Maximum } \\
\text { illuminance }\end{array}$ & $\begin{array}{c}\text { Average } \\
\text { luminance }\end{array}$ & $\begin{array}{c}\text { Maximum } \\
\text { luminance }\end{array}$ \\
\hline $\boldsymbol{l} \boldsymbol{x}$ & $\boldsymbol{l} \boldsymbol{x}$ & $\boldsymbol{c d} / \boldsymbol{m} \boldsymbol{2}$ & $\boldsymbol{c d} / \boldsymbol{m} \mathbf{2}$ \\
\hline 5.59 & 132 & 0.43 & 101.77 \\
\hline
\end{tabular}

As can be seen from Table 3, through the analysis of the simulation results of, the illuminance of the automobile headlights in high-altitude highway tunnel is $5.591 \mathrm{x}$ and the luminance is $0.43 \mathrm{~cd} / \mathrm{m}^{2}$

\section{Lighting design standard for interior zone of high-altitude highway tunnel based on the supplementary lighting of automobile headlights}

The method of combining automobile headlights lighting and tunnel lighting is adopted. The recommended luminance for interior zone of plateau highway tunnel is taken as the standard. The value which reduces the luminance of automobile headlights is regarded as the design value of the energy-saving lighting of high-altitude highway tunnel. The Lighting design standard for interior zone of high-altitude highway tunnel is shown in formula (5):

$$
\mathrm{L}=\mathrm{L} 1-\mathrm{L} 2
$$

In the formula, $\mathrm{L}$ is lighting design standard for the interior zone of high-altitude highway tunnel, $\mathrm{cd} / \mathrm{m}^{2} . \mathrm{L} 1$ is recommended luminance for interior zone of plateau highway tunnel, cd $/ \mathrm{m}^{2}$. L2 is luminance of automobile headlights, $\mathrm{cd} / \mathrm{m}^{2}$.

According to formula (5), recommended luminance for interior zone of highway tunnel (take $40 \mathrm{~km} / \mathrm{h}$ as an example) under different altitudes can be obtained, as shown in Table 4.
Table 4. Recommended luminance for interior zone of highway tunnel.

\begin{tabular}{|c|c|c|c|c|}
\hline Altitude(m) & $\mathbf{2 0 0 0}$ & $\mathbf{3 0 0 0}$ & $\mathbf{4 0 0 0}$ & $\mathbf{5 0 0 0}$ \\
\hline $\begin{array}{c}\text { Recommended } \\
\text { luminance } \\
(\mathrm{cd} / \mathrm{m} 2)\end{array}$ & 0.73 & 0.82 & 0.91 & 1.0 \\
\hline
\end{tabular}

\section{Conclusions}

In this study, the energy-saving standard for interior zone of high-altitude highway tunnel is defined. Lighting design based on the recommended luminance values can effectively save lighting operation cost. The following main conclusions are drawn:

(1) Considering altitude, luminance in the tunnel, vehicle speed, and other factors, it is clear that luminance of interior zone required in lighting design increases with the increase of altitude, and all are greater than the lighting design values in current standard.

(2) Through simulations of the luminance of automotive headlights in tunnel, the minimum luminance value of the automotive headlights in high- altitude highway tunnel is $0.43 \mathrm{~cd} / \mathrm{m}^{2}$.

(3) Considering the influence of automotive headlights, the lighting design standard for the interior zone of high-altitude highway tunnel(design speed is $40 \mathrm{~km} / \mathrm{h}$ ) is obtained. When the altitude is $2000 \mathrm{~m}, 3000 \mathrm{~m}$, $4000 \mathrm{~m}$ and $5000 \mathrm{~m}$ respectively, the lighting design standard for interior zone of high-altitude highway tunnel is $0.73 \mathrm{~cd} / \mathrm{m}^{2}, 0.82 \mathrm{~cd} / \mathrm{m}^{2}, 0.91 \mathrm{~cd} / \mathrm{m}^{2}, 1.0 \mathrm{~cd} / \mathrm{m}^{2}$.

\section{Acknowledgment}

Fund Project: National Natural Science Foundation of China(51908387); Sichuan Agricultural University Scientific Research Interest Cultivation Project(2019674); National Undergraduate Training Program for Innovation and Entrepreneurship(201910626027)

\section{References}

1. Sichuan Provincial Civil Engineering Society Tunnel Professional Committee,2016"Sichuan Province Tunnel Construction Statistics Report".

2. Zheng Xiujuan,LiZhanheng,Zhang Yun. Eye Movement Research and Development of Driving Safety[J]. Technology and innovation management,2018,39(01):50-59.

3. Ministry of Transport of the People's Republic of China.Guidelines for Design of Lighting of Highway Tunnels: JTG/T D70/2-01-2014[S]. Beijing: China Communications Pressco.LTD,2014.

4. Ministry of Transport of the People's Republic of China.Code for Design of Road Tunnel: JTG D70-2004[S]. Beijing: China Communications Press, 2004.

5. Zhang Xiaoqin,HuBijiang,WaMeng. Roadway brightness requirement based on driving visibility 
requirements[J]. Beijing: Journal of industrial university , 2016, 42(05):768-773.

6. Wang Yanan.Analysis on the Influence of Tunnel Lighting Environment on Driver's Reaction Time.Xi'an:Chang'anUniversity, Master Thesis, 2017.

7. Li Ke. Study on Energy Saving Technology of Lighting Sichuan Plateau LowtrafficTunnel[D]. Southwest Jiaotong University, 2018.

8. Ministry of Transport of the People's Republic of China. Specifications for Design of Ventilation andLighting of Highway Tunnel: JT/J026.1-1999 [S]. Beijing: China Communications Press,2000. 